\title{
Article \\ Resistivity Testing of Palladium Dilution Limits in CoPd Alloys for Hydrogen Storage
}

\author{
Sudhansu Sekhar Das $\left.{ }^{1,2}{ }^{(}\right)$, Gregory Kopnov ${ }^{1}$ and Alexander Gerber ${ }^{1, *}$ \\ 1 School of Physics and Astronomy, Tel Aviv University, Ramat Aviv, Tel Aviv 69978, Israel; \\ sudhansu@tauex.tau.ac.il (S.S.D.); kopnov@tauex.tau.ac.il (G.K.) \\ 2 School of Physical Science, National Institute of Science Education and Research Bhubaneswar, \\ Jatni 752050, India \\ * Correspondence: gerber@tauex.tau.ac.il
}

Citation: Das, S.S.; Kopnov, G.; Gerber, A. Resistivity Testing of Palladium Dilution Limits in CoPd Alloys for Hydrogen Storage. Materials 2022, 15, 111. https:// doi.org/10.3390/ma15010111

Academic Editor: Tomasz Czujko

Received: 4 November 2021

Accepted: 20 December 2021

Published: 24 December 2021

Publisher's Note: MDPI stays neutral with regard to jurisdictional claims in published maps and institutional affiliations.

Copyright: (c) 2021 by the authors Licensee MDPI, Basel, Switzerland. This article is an open access article distributed under the terms and conditions of the Creative Commons Attribution (CC BY) license (https:// creativecommons.org/licenses/by/ $4.0 /)$.

\begin{abstract}
Palladium satisfies most of the requirements for an effective hydrogen storage material with two major drawbacks: it has a relatively low gravimetric hydrogen density and is prohibitively expensive for large scale applications. Pd-based alloys should be considered as possible alternatives to a pure $\mathrm{Pd}$. The question is how much one can dilute the Pd concentration in a variety of candidate materials while preserving the hydrogen absorption capability. We demonstrate that the resistivity measurements of thin film alloy samples can be used for a qualitative high-throughput screening and study of the hydrogen absorbing properties over the entire range of palladium concentrations. Contrary to palladium-rich alloys where additional hydrogen scattering indicates a degree of hydrogen content, the diluted alloy films respond by a decrease in resistance due to their thickness expansion. Evidence of significant hydrogen absorption was found in thin CoPd films diluted to just $20 \%$ of Pd.
\end{abstract}

Keywords: hydrogen storage; palladium alloys; thin films

\section{Introduction}

A hydrogen-based economy is one of the favorite approaches to maintaining the current technological progress and standards of living while lowering carbon dioxide emissions [1,2]. Unlike fossil fuels, the combustion of hydrogen does not generate carbon dioxide $\left(\mathrm{CO}_{2}\right)$, but water vapor only. The ultimate goals of a hydrogen-based economy include the production of hydrogen while generating minimal greenhouse gases, the development of efficient infrastructures for hydrogen storage and transport and harnessing its energy via fuel cells. Hydrogen storage and transportation are critical prerequisites to the realization of this vision and are among the most challenging issues to overcome. Hydrogen may be stored either under high pressure as a gas, cryogenically as a liquid, or in the solid state as a hydride [3-6]. The latter option offers the best theoretical combination of gravimetric and volumetric capacity, stability and safety. The search for the optimal storage materials is far from being accomplished. The hydride materials studied thus far either can work near room temperature but have low gravimetric density or have high gravimetric density but slow kinetics and can only release hydrogen at high temperatures.

Palladium has the potential to play a major role in practically every aspect of the envisioned hydrogen economy owing to its catalytic and hydrogen absorbing properties $[7,8]$. Contrary to the majority of the known metal hydrides, palladium can absorb large quantities of hydrogen at room temperature and atmospheric pressure due to the dissociative adsorption of $\mathrm{H}_{2}$ molecules. It satisfies most of the requirements for an effective hydrogen storage material with two major drawbacks: it has a relatively low gravimetric hydrogen density (Pd is a heavy metal) [9] and is prohibitively expensive for large scale applications. Pd-based alloys should be considered as possible replacements to a pure Pd for reducing the cost, increasing the gravimetric hydrogen density capacity and, probably, improving the diffusivity and kinetics of hydrogen loading and release. Multiple studies were devoted 
to the thermodynamics and solubility of hydrogen in Pd alloys [10,11]; however, most of these works were limited to the alloys with a relatively low solute metal content [12-18]. Studies of alloys with strongly diluted Pd (up to about 50\%) are focused mainly on the permeability of selected binary and ternary alloy membranes $[19,20]$.]

$\mathrm{Pd}$ forms alloys with a spectrum of metals, such as fcc $\mathrm{Cu}, \mathrm{Ag}, \mathrm{Pt}, \mathrm{Al}, \mathrm{Ni}$, and bcc $\mathrm{Fe}, \mathrm{V}, \mathrm{Nb}, \mathrm{Ta}$, Mo and $\mathrm{W}$. The number of potential materials for hydrogen storage is very large and to identify the optimal ones, multiple samples have to be produced and tested. For that, using combinatorial methods to study and develop new materials can be highly useful. A high throughput (combinatorial) materials' science methodology is a relatively new research paradigm that offers the promise of rapid and efficient materials screening, optimization and discovery. High-throughput experiments are characterized by a synthesis of a "library" sample that contains the materials variation of interest (typical composition), and rapid and localized measurement schemes that result in massive data sets [21]. The goal of any hydrogen storage program is to manufacture materials on a kilogram scale. However, for rapid fabrication and screening purposes, it is more efficient to produce thin film samples with a wide range of compositional variations using standard film deposition techniques [22]. Traditional volumetric [23,24] and gravimetric [25] measurements of hydrogen absorption cannot be used with thin film samples due to a negligible amount of the active material. Thus, indirect screening techniques have to be used.

Hydrogen absorption in metals can be detected by monitoring characteristic changes in the crystallographic and electronic band structure of the host materials. Hydrogen occupies the interstitial sites in the fcc and bcc lattices and causes a large expansion of the host crystal [26]. The lattice expansion can be measured using various structure characterization tools, such as X-ray and neutron diffraction [27] but the adaptation of these techniques for a rapid and massive screening is challenging. A technically simpler method of lattice expansion detection was suggested about a decade ago [28], in which extension of the hydrogenated film deposited on a bending cantilever was sensed by the deflected laser beams. The technique was suggested for a possible high-throughput screening and tested with several Mg-based samples. Another property affected by hydrogen absorption is electrical resistivity. Metallic $\mathrm{Mg}$ becomes insulating and optically transparent when it transforms to magnesium hydride, the property used in the hydrogenography screening technique [29]. Pd, on the other hand, remains metallic in the hydride state, and its resistance can either increase or decrease in response to hydrogen absorption. An increase in the resistance is attributed to an enhancement of electron scattering in the hydride phase. The effect was extensively studied and used for constructing the hydrogen metal phase diagrams [30] and in hydrogen detection systems [31,32]. A reduction in the resistivity at hydrogen loading was observed in ultrathin and nano-gap films [33-36] and attributed to the lateral swelling of separated grains. As a result, the metallic clusters touch and create new conducting channels or shrink the inter-particle gaps, which results in an overall decrease in resistance. However, as demonstrated recently [37], the reduction in resistance in the hydrogenated state is not restricted to the nano-gap structures but is a general property of thin films grown on rigid substrates. Adhesion to the substrate surface prevents the lateral expansion of the hydrogenated films. Absence of the in-plane expansion is transformed to the out-of-plane extension enhanced by Poisson's effect. The elastic thickness expansion can reach $12.6 \%$ if the atomic ratio between $\mathrm{Pd}$ and the absorbed hydrogen is one [38]. Expanding the thickness increases the current flow cross-section and reduces the measured electrical resistance. The change in the resistivity between the hydrogen-free and the hydrogenated states is a superposition of the enhanced hydride scattering $\Delta \rho_{H}$ and a reduction in the resistance due to the thickness expansion, which can be presented as follows:

$$
\Delta \rho=\frac{1}{1+\gamma}\left(\Delta \rho_{H}-\gamma \rho_{0}\right)
$$

where $\rho_{0}$ is the resistivity before hydrogen loading, and $\gamma=\Delta t / t_{0}$ is the thickness expansion coefficient (strain). The negative thickness expansion term $\left(-\gamma \rho_{0}\right)$ is proportional to 
the initial resistivity and can be much larger than the positive hydride scattering term in the high resistivity samples. In bulk Pd and the low resistivity thick films, the scattering term is dominant. On the other hand, the thickness expansion term is expected to dominate in thin films with an enhanced surface scattering and alloys with high electrical resistivity. Indeed, the resistance response polarity of thin $\mathrm{Pd}$, thick $\mathrm{PdSiO}_{2}$ granular mixtures and CoPd alloy films was found to change from positive to negative at the resistivity threshold of $50 \mu \Omega \mathrm{cm}$ in a $4 \% \mathrm{H}_{2}$ atmosphere [37]. As a rule, the resistivity of binary palladium alloys increases with the increasing concentration of the alloying component. For example, the alloying of $\mathrm{Pd}$ with about $10 \%$ of $\mathrm{V}, \mathrm{Nb}$, or Mo increases the room temperature resistivity by a factor of 4-8 [39]. The lattice expansion term in films with such resistivity is expected to be large and easily detected.

The resistance measurements allow us not only to establish the very fact of hydrogen absorption but can also provide valuable information on the kinetics of the processes involved. As was demonstrated in Ref. [40], the time dependence of the hydride scattering term can differ significantly from the lattice response one. It was suggested that loading the metal host with a large amount of hydrogen can create an out-of-equilibrium state. The stress built up by a rapid hydrogen absorption is released by a plastic lattice expansion. The latter can be much slower than the gas diffusion process. Thus, the lattice expansion associated with hydrogen absorption can be observable after a significant delay. The ability to differentiate between the hydrogen diffusion and the lattice response, between the reversible elastic and the irreversible plastic deformations is valuable for a basic understanding of the hydrogenation mechanisms.

Here, we demonstrate the resistive testing of hydrogen absorption in CoPd alloys over a full range of palladium concentrations. We will show the evidence of hydrogen absorption in the alloys containing just $20 \% \mathrm{Pd}$.

\section{Experimental}

Co and Pd are soluble and form an equilibrium fcc solid solution phase at all compositions at room temperature [41]. Ferromagnetic CoPd alloys were used recently for magnetic and spintronics detection of hydrogen [42-45]. 15-nanometer-thick polycrystalline $\mathrm{Co}_{x} \mathrm{Pd}_{100-x}$ films were grown by rf-magnetron sputtering onto room-temperature glass substrates from two separate targets $(99.99 \%) \mathrm{Co}$ and $\mathrm{Pd}$ in the custom made deposition system., Co atomic concentrations covered the entire range $0 \leq x \leq 100$. The base pressure prior to deposition was $5 \times 10^{-7}$ mbar. Sputtering was carried out at an Ar pressure of $5 \times$ $10^{-3}$ mbar. Composition of samples was controlled by rf-power of the respective sputtering sources. The typical deposition rate was $0.01-0.1 \mathrm{~nm} / \mathrm{s}$. No post-deposition annealing was used. After the deposition, the samples were mounted on the sample holder and connected with 20-millimeter Si / Al wire using the wire-bonder. Resistance was measured following the Van der Pauw protocol. The measurement setup included the GMV 3473 electromagnet, Keithley 2400 source/meter, Keithley 2001 multimeter and HP 3488A switch/control unit. The effect of hydrogen absorption was determined from measurements conducted in nitrogen and a $4 \% \mathrm{H}_{2} / \mathrm{N}_{2}$ mixture gas at an ambient pressure and room temperature.

\section{Results and Discussion}

Accurate resistivity measurements of thick palladium films can be challenging because of buckling and cracks developing in the process of hydrogen absorption due to the high compressive stress. An example of such damage in 20-nanometer-thick Pd film is illustrated in Figure 1a,b. On the other hand, 15-nanometer-thick and thinner films of Pd and CoPd alloys in the entire concentrations range are mechanically stable under repeated hydrogenation and dehydrogenation cycles, and no buckling or cracks were detected in any sample. Micrographs of the $\mathrm{Co}_{30} \mathrm{Pd}_{70}$ film surface before and after a hydrogenation-dehydrogenation cycle are shown in Figure 1c,d. The 15-nanometer-thick films are continuous and uniform. Films thinner than $10 \mathrm{~nm}$ have an inhomogeneous meandric morphology with a continuous percolating metallic path across the sample. Films 
with a thickness below $3 \mathrm{~nm}$ are discontinuous and not conducting. Thus, mechanically stable, uniform 15-nanometer-thick films were selected for this study.
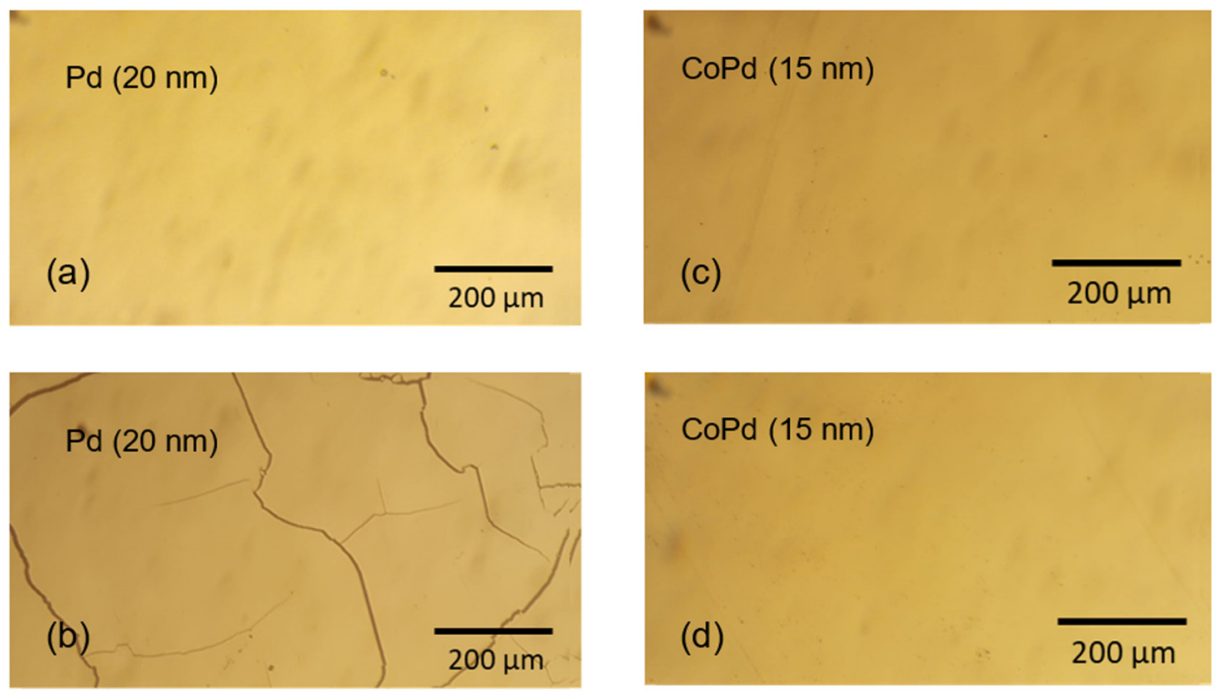

Figure 1. Micrographs of 20-nanometer-thick $\mathrm{Pd}(\mathbf{a}, \mathbf{b})$, and 15-nanometer-thick $\mathrm{Co}_{30} \mathrm{Pd}_{70}(\mathbf{c}, \mathbf{d})$ film surfaces before and after the hydrogenation-dehydrogenation cycle, respectively. Cracks are visible on the surface of hydrogenated Pd film.

Figure 2 presents the time dependent resistivity response to a sequence of hydrogen loading and unloading cycles (sequential exposure to $1 \mathrm{~atm} 4 \% \mathrm{H}_{2} / \mathrm{N}_{2}$ mixture followed by $\mathrm{N}_{2}$ ) of three $\mathrm{Co}_{x} \mathrm{Pd}_{100-x}$ samples with $\mathrm{x}=10(\mathrm{a}), \mathrm{x}=40$ (b) and $\mathrm{x}=80$ (c).

The starting resistivity grows gradually with the Co content increasing from $35 \mu \Omega \mathrm{cm}$ in $\mathrm{Co}_{10} \mathrm{Pd}_{90}$ to $110 \mu \Omega \mathrm{cm}$ in $\mathrm{Co}_{40} \mathrm{Pd}_{60}$. The first exposure to hydrogen is different in samples with a different $\mathrm{Co}$ concentration and resistivity. Resistance increases in the low resistivity $\mathrm{Co}_{10} \mathrm{Pd}_{90}(\mathrm{a})$ and decreases in samples with higher resistivity $\left(\rho_{0}>50 \mu \Omega \mathrm{cm}\right)$. The response to hydrogen removal is similar in samples (a) and (b): resistance decreases and saturates in $\mathrm{N}_{2}$. The further response is reproducible and similar in all films: resistance increases when exposed to hydrogen and drops on its removal. The sequence of reproducible rapid increase/decrease responses to the loading/unloading of hydrogen superposed with an irreversible gradual reduction in resistivity can be interpreted as a superposition of reversible hydride formation-removal signals in the background of the irreversible thickness inflation. The response of low resistivity films is dominated by the hydride scattering term, while the lattice expansion is dominant in the high resistivity alloys. The reversible hydride formation-removal signal is negligibly small in the $\mathrm{Co}_{80} \mathrm{Pd}_{20}$ sample, and an irreversible reduction in resistivity is the only signal observed.

A different reversibility allows us to distinguish between the reversible hydrogen scattering and the irreversible lattice expansion contributions. The lattice expansion can be a long process depending not on the number of hydrogenation-dehydrogenation cycles, but the duration of exposure to hydrogen. The process is irreversible in nitrogen-heliumnitrogen cycling. The magnitude of this expansion resistivity change was determined as the difference between the initial resistivity in nitrogen and the final one when the expansion process was over.

The scattering term is reproducible over a large number of hydrogenation-dehydrogenation cycles, as seen, e.g., in Figure 2a. Moreover, the alloys kept their sorption-desorption capability for a long time, and the scattering response did not change significantly when it was re-tested about a year after the fabrication. The magnitude of the effect decreases with an increasing Co content. Figure 3 presents the relative values of the scattering component, the thickness expansion term and the total resistance change as a function of the Co content. 

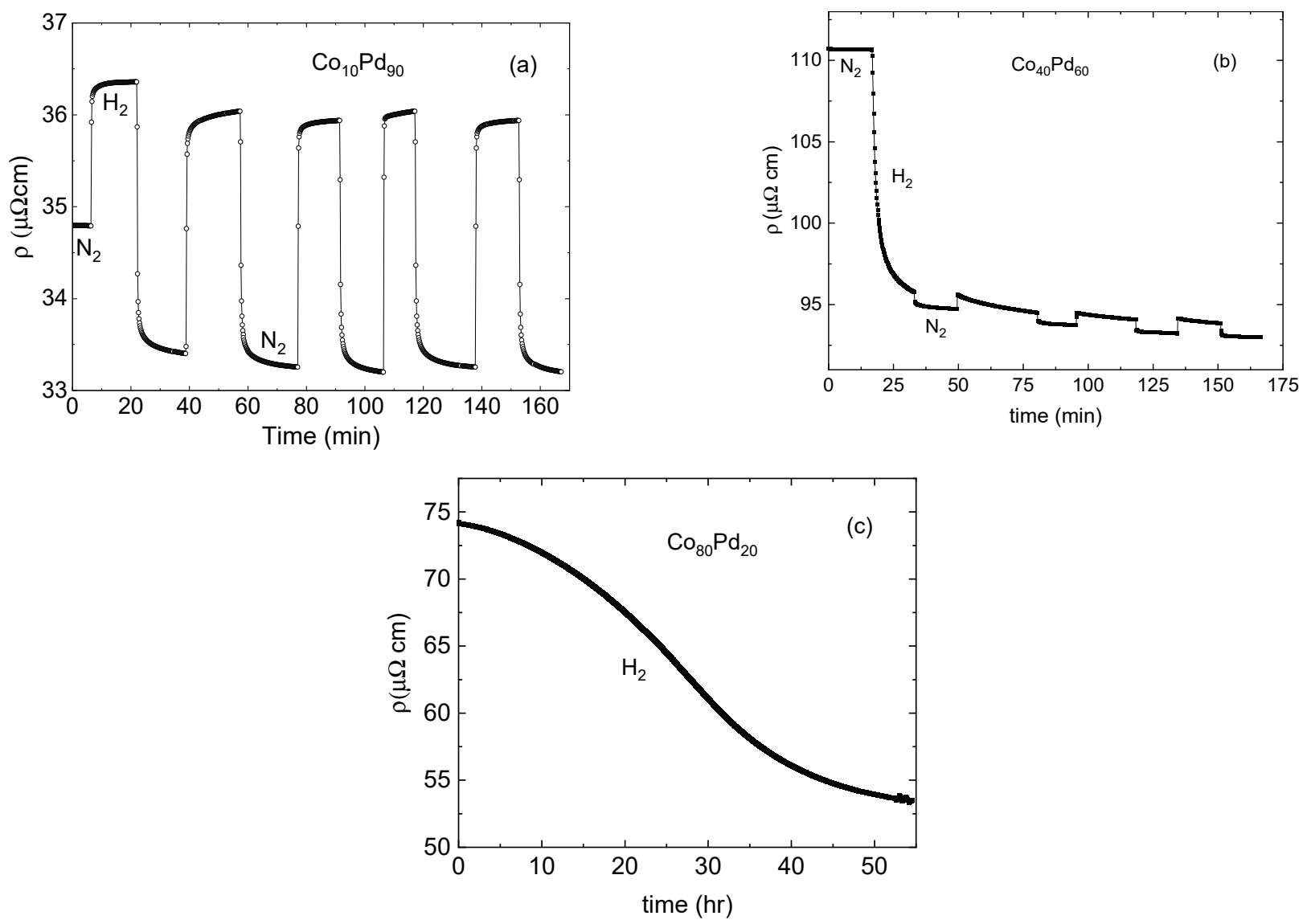

Figure 2. Resistivity response to a sequence of hydrogenation and dehydrogenation cycles (sequential exposure to $1 \mathrm{~atm} 4 \% \mathrm{H}_{2} / \mathrm{N}_{2}$ gaseous mixture followed by $\mathrm{N}_{2}$ ) of three 15-nanometer-thick $\mathrm{Co}_{\mathrm{x}} \mathrm{Pd}_{100-\mathrm{x}}$ samples with $\mathrm{x}=10(\mathbf{a}), \mathrm{x}=40(\mathbf{b})$ and $\mathrm{x}=80(\mathbf{c})$.

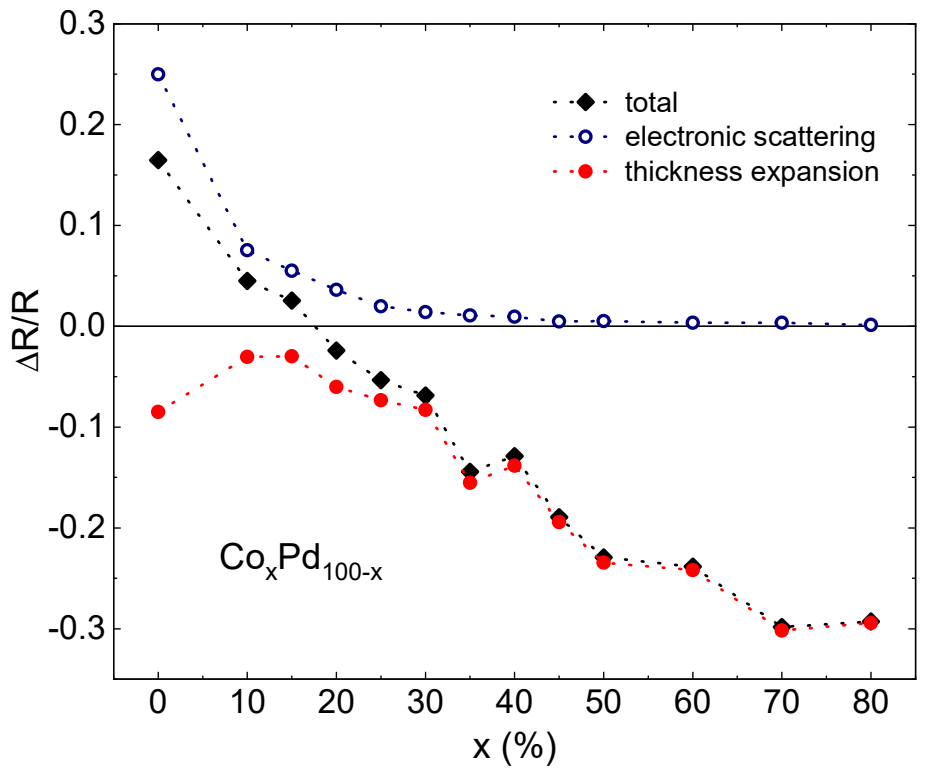

Figure 3. The normalized resistance response to hydrogenation of $\mathrm{CoPd}$ films as a function of $\mathrm{Co}$ content x. Open dots indicate the electronic scattering term, solid dots-the thickness expansion term, and crosses-the total resistance change. 
The electronic scattering term is about $25 \%$ in pure Pd, decreases with the Co concentration and becomes very small at $x>40 \%$. On the other hand, the magnitude of the negative expansion term increases with the Co concentration and is the largest at $\mathrm{x}=70-80 \%$ before dropping to zero in pure Co. Co does not absorb hydrogen and no resistance changes were observed when a pure Co sample was exposed to hydrogen. Notably, the alloy samples with as much as $80 \%$ Co demonstrated a strong lattice expansion response to hydrogen exposure, indicating hydrogen absorption.

The magnitude of the expansion response in strongly diluted alloys is very large; however, the kinetics of the lattice expansion is very slow. Figure 4 presents the effective half-time of the thickness expansion $T_{50}$, defined as the time at which the irreversible resistance reduction changed by half, as a function of the Co concentration $x$.

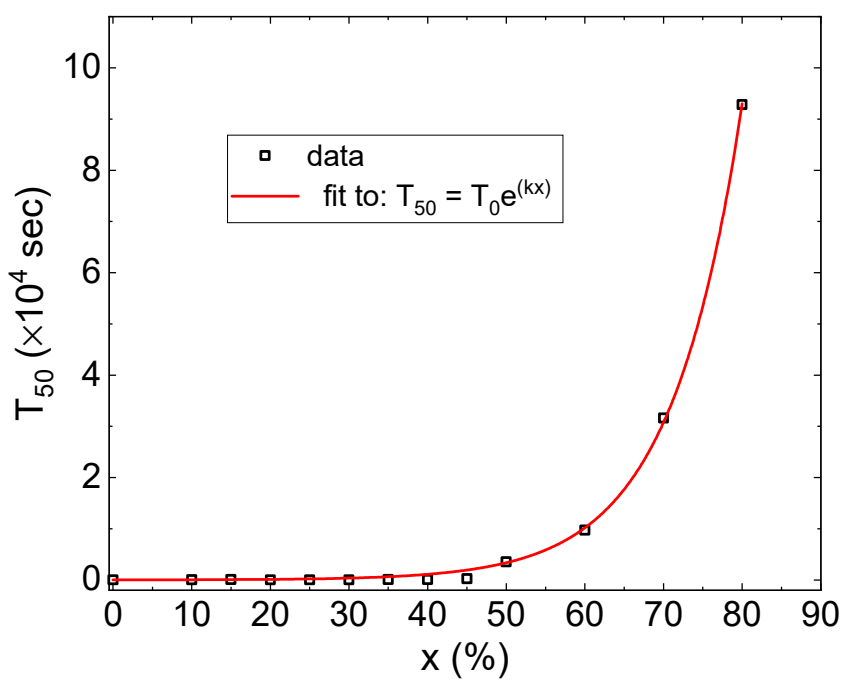

Figure 4. The half-time of the thickness expansion $T_{50}$ as a function of Co concentration $x$ (open squares). Solid line (red) is a fit to $T_{50}=T_{0} e^{k x}$, with $T_{0}=13 \mathrm{~s}$ and $k=0.1$.

Hydrogen diffusion and the hydride formation accelerates with an increasing Co content down to a few sec in $\mathrm{Co}_{40} \mathrm{Pd}_{60}$ [40], which is quicker than in pure $\mathrm{Pd}$. An enhanced diffusivity rate in these strongly diluted Pd-Co films is consistent with the conclusions of earlier studies of Pd-Au and Pd-Ag membranes [46,47] and Au-alloyed Pd surfaces [48]. The thickness expansion time scale is very different from the hydrogen diffusion one: $10 \mathrm{~s}$ in the $x=10$ sample up to $10^{5} \mathrm{~s}$ in the $\mathrm{x}=80 \%$ one. $T_{50}$ is fitted well as follows:

$$
T_{50}=T_{0} e^{k x}
$$

where $T_{0}=13 \mathrm{~s}$ and $k=0.1$ (red dashed line in Figure 4), i.e., it increases exponentially with the Co concentration. The diffusion of hydrogen in and out of the material can be much quicker than the respective lattice response. The effect is interpreted as due to the creation of a non-equilibrium hydride state in which stress is built up rapidly with hydrogen absorption and is released by a slow plastic thickness growth that can be orders of magnitude slower than the gas diffusion time.

The resistivity measurements presented here provide qualitative evidence of hydrogen absorption in CoPd alloys but not quantitative information on the hydrogen content. They can be used for a high-throughput preliminary screening of alloys to evaluate the limits of palladium dilution. However, calibration of the resistance response by, e.g., explicit volumetric measurements of macroscopic samples is required to evaluate the quantity of the stored hydrogen.

To summarize, we used the time-dependent resistivity measurements to study the absorption capabilities of $\mathrm{Co}_{\mathrm{x}} \mathrm{Pd}_{100-x}$ films over a full range of $\mathrm{Pd}$ concentrations and found clear evidence of hydrogen absorption in strongly diluted (down to $20 \%$ of Pd) alloys. The 
dominant mechanism of the resistance response to hydrogen absorption in low resistivity Pd-rich alloys is scattering by interstitial hydrogen atoms. In high resistivity Pd-poor alloys, the scattering mechanism becomes negligible. Instead, the reduction in resistivity due to the lattice expansion is large and easily detectable. The lattice expansion and the respective reduction in resistivity are expected to be a general property of any hydrogen absorbing material. Resistivity measurements are technically simple and rapid. We propose to use the phenomenon and the method for high-throughput qualitative screening and study the hydrogen-absorbing kinetics of Pd-based alloys. Our next step will be alloying Pd with cheap and abundant $\mathrm{Cu}$ and $\mathrm{Al}$.

\section{Conclusions}

1. Thin films (below $15 \mathrm{~nm}$ thick) of Pd and CoPd alloys are mechanically stable under repeated hydrogenation and dehydrogenation cycles, which allowed us to perform reliable and reproducible resistivity measurements.

2. The change in the resistivity between the hydrogen-free and the hydrogenated states is a superposition of the enhanced hydride scattering and reduction in the resistance due to the thickness expansion.

3. The response of low resistivity Pd-rich films to hydrogenation is dominated by the hydride scattering term.

4. The reduction in resistivity due to the lattice expansion is dominant in high resistivity Pd-poor alloys.

5. Evidence of significant hydrogen absorption was found in $\mathrm{CoPd}$ alloys diluted to just $20 \%$ Pd.

6. The time scale of lattice expansion due to hydrogen absorption increases exponentially with the Co concentration.

7. Resistivity measurements can be used for the qualitative high-throughput screening of Pd-based alloys over the entire concentration range.

Author Contributions: Investigation S.S.D. and G.K., supervision and writing A.G. All authors have read and agreed to the published version of the manuscript.

Funding: This research was funded by the Israel Science Foundation grant No. 992/17.

Data Availability Statement: The data that support the findings of this study are available within the article.

Conflicts of Interest: The authors declare no conflict of interest.

\section{References}

1. Brandon, N.P.; Kurban, Z. Clean energy and the hydrogen economy. Phil. Trans. R. Soc. A 2017, 375, 20160400. [CrossRef] [PubMed]

2. Gielen, D.; Taibi, E.; Miranda, R. Hydrogen: A Renewable Energy Perspective; International Renewable Energy Agency (IRENA): Abu Dhabi, United Arab Emirates, 2019; ISBN 978-92-9260-151-5.

3. Rönnebro, E.C.E.; Majzoub, E.H. Recent advances in metal hydrides for clean energy applications. MRS Bull. $2013,38,452$. [CrossRef]

4. Abe, J.O.; Popoola, A.P.I.; Ajenifuja, E.; Popoola, O.M. Hydrogen energy, economy and storage: Review and recommendation. Int. J. Hydrog. Energy 2019, 44, 15072. [CrossRef]

5. Hirscher, M.; Yartys, V.A.; Baricco, M.; von Colbe, J.B.; Blanchard, D.; Bowman, R.C., Jr.; Broom, D.P.; Buckley, C.E.; Chang, F.; Chen, P. Materials for hydrogen-based energy storage: Past, recent progress and future outlook. J. Alloy. Compd. 2020, 827, 153548. [CrossRef]

6. Lai, Q.; Sun, Y.; Wang, T.; Modi, P.; Cazorla, C.; Demirci, U.; Fernandez, J.; Leardini, F.; Aguey-Zinsou, K. How to Design Hydrogen Storage Materials? Fundamentals, Synthesis, and Storage Tanks. Adv. Sustainable Syst. 2019, 3, 1900043. [CrossRef]

7. Adams, B.D.; Chen, A. The role of palladium in a hydrogen economy. Mater. Today 2011, 14, 282. [CrossRef]

8. Dekura, S.; Kobayashi, H.; Kusada, K.; Kitagawa, H. Hydrogen in Palladium and Storage Properties of Related Nanomaterials: Size, Shape, Alloying, and Metal-Organic Framework Coating Effects. Chem. Phys. Chem. 2019, 20, 1158. [CrossRef]

9. Grochala, W.; Edwards, P.P. Thermal decomposition of the non-interstitial hydrides for the storage and production of hydrogen. Chem. Rev. 2004, 104, 1283. [CrossRef] 
10. Sakamoto, Y.; Chen, F.L.; Ura, M.; Flanagan, T.B. Thermodynamic Properties for Solution of Hydrogen in Palladium-Based Binary Alloys. Ber. Bunsenges. Phys. Chem. 1995, 99, 807. [CrossRef]

11. Griessen, R.; Driessen, A. Heat of formation and band structure of binary and ternary metal hydrides. Phys. Rev. B 1984, 30,4372 . [CrossRef]

12. Lewis, F.A.; Kandsamy, K.; McNicholl, R.A.; Tong, X.Q. Hydrogen pressure-hydrogen content relationship of palladium and palladium alloy-hydrogen systems. Int. J. Hydrog. Energy 1995, 20, 369. [CrossRef]

13. Yoshihara, M.; McLellan, R.B. The diffusivity of hydrogen in palladium-based solid solutions. Acta Metall. 1982, $30,1605$. [CrossRef]

14. Maestas, S.; Flanagan, T.B. Diffusion of hydrogen in gold-palladium alloys. J. Phys. Chem. 1973, 77, 850. [CrossRef]

15. Züchner, H. Investigation of the diffusion of hydrogen in Pd- and Pd/Ag alloys by means of a current pulse method. Z Naturforsch. A 1970, 25, 1490. [CrossRef]

16. McLellan, R.B.; Kirchheim, R. The thermodynamics of palladium-based solid solutions containing a noble-metal substitutional solute and hydrogen. J. Phys. Chem. Solids 1981, 42, 157. [CrossRef]

17. Barlag, H.; Opara, L.; Züchner, H. Hydrogen diffusion in palladium based f.c.c. alloys. J. Alloy. Compd. 2002, 330, 434. [CrossRef]

18. Baba, K.; Miyagawa, U.; Watanabe, K.; Sakamoto, Y.; Flanagan, T.B. Electrical resistivity changes due to interstitial hydrogen in palladium-rich substitutional alloys. J. Mater. Sci. 1990, 25, 3910. [CrossRef]

19. Peters, T.A.; Kaleta, T.; Stange, M.; Bredesen, R. Development of thin binary and ternary Pd-based alloy membranes for use in hydrogen production. J. Membr. Sci. 2011, 383, 124. [CrossRef]

20. Bosko, M.L.; Fontana, A.D.; Tarditi, A.; Cornaglia, L. Advances in hydrogen selective membranes based on palladium ternary alloys. Int. J. Hydrog. Energy 2021, 46, 15572. [CrossRef]

21. Green, M.L.; Takeuchi, I.; Hattrick-Simpers, J.R. Applications of high throughput (combinatorial) methodologies to electronic, magnetic, optical, and energy-related materials. J. Appl. Phys. 2013, 113, 231101. [CrossRef]

22. Baldi, A.; Dam, B. Thin film metal hydrides for hydrogen storage applications. J. Mater. Chem. 2011, 21, 4021. [CrossRef]

23. Vajo, J.J.; Mertens, F.; Ahn, C.C.; Bowman, R.C.; Fultz, B. Altering Hydrogen Storage Properties by Hydride Destabilization through Alloy Formation: $\mathrm{LiH}$ and $\mathrm{MgH}_{2}$ Destabilized with Si. J. Phys. Chem. B 2004, 108, 13977. [CrossRef]

24. Bogdanovic, B.; Schwickardi, M. Ti-doped alkali metal aluminium hydrides as potential novel reversible hydrogen storage materials. J. Alloys Compd. 1997, 1, 253-254. [CrossRef]

25. Chen, J.; Kuriyama, N.; Xu, Q.; Takeshita, H.T.; Sakai, T. Reversible Hydrogen Storage via Titanium-Catalyzed LiAlH 4 and $\mathrm{Li}_{3} \mathrm{AlH}_{6}$. J. Phys. Chem. B 2001, 105, 11214. [CrossRef]

26. Fukai, Y. The Metal-Hydrogen System: Basic Bulk Properties; Springer Series in Materials Science; Springer: Berlin/Heidelberg, Germany, 2005; Volume 21.

27. Callori, S.J.; Rehm, C.; Causer, G.L.; Kostylev, M.; Klose, F. Hydrogen Absorption in Metal Thin Films and Heterostructures Investigated in Situ with Neutron and X-ray Scattering. Metals 2016, 6, 125. [CrossRef]

28. Ludwig, A.; Cao, J.; Savan, A.; Ehmann, M. High-throughput characterization of hydrogen storage materials using thin films on micromachined Si substrates. J. Alloys Compd. 2007, 446, 516. [CrossRef]

29. Gremaud, R.; Broedersz, C.P.; Borsa, D.M.; Borgschulte, A.; Mauron, P.; Schreuders, H.; Rector, J.H.; Dam, B.; Griessen, R. Hydrogenography: An Optical Combinatorial Method to Find New Light-Weight Hydrogen-Storage Materials. Adv. Mater. 2007, 19, 2813. [CrossRef]

30. Manchester, F.D. Phase Diagrams of Binary Hydrogen Alloys; ASM International: Materials Park, OH, USA, 2000.

31. Hübert, T.; Boon-Brett, L.; Black, G.; Banach, U. Hydrogen sensors-A review. Sens. Actuators B Chem. 2011, 157, 329. [CrossRef]

32. Mirzaei, A.; Yousefi, H.R.; Falsafi, F.; Bonyani, M.; Lee, J.-H.; Kim, J.-H.; Kim, H.W.; Kim, S.S. An overview on how Pd on resistive-based nanomaterial gas sensors can enhance response toward hydrogen gas. Int. J. Hydrog. Energy 2019, $44,20552$. [CrossRef]

33. Favier, F.; Walter, E.C.; Zach, M.P.; Benter, T.; Penner, R.M. Hydrogen Sensors and Switches from Electrodeposited Palladium Mesowire Arrays. Science 2001, 293, 2227. [CrossRef]

34. Wagner, S.; Hamm, M.; Pundt, A. Huge hydrogen-induced resistive switching in percolating palladium thin films. Scr. Mater. 2013, 69, 756. [CrossRef]

35. Zhao, M.; Wong, M.H.; Ong, C.W. Achievement of controlled resistive response of nanogapped palladium film to hydrogen. Appl. Phys. Lett. 2015, 107, 033108. [CrossRef]

36. Nakamura, N.; Ueno, T.; Ogi, H. Hydrogen-gas sensing at low concentrations using extremely narrow gap palladium nanoclusters prepared by resistive spectroscopy. J. Appl. Phys. 2019, 126, 225104. [CrossRef]

37. Das, S.S.; Kopnov, G.; Gerber, A. Positive versus negative resistance response to hydrogenation in palladium and its alloys. AIP Adv. 2020, 10, 065129. [CrossRef]

38. Wagner, S.; Kramer, T.; Uchida, H.; Dobron, P.; Cizek, J.; Pundt, A. Mechanical stress and stress release channels in 10-350 nm palladium hydrogen thin films with different micro-structures. Acta Mater. 2016, 114, 116. [CrossRef]

39. Kudielka-Artner, E.; Argent, B.B. Magnetic and other Properties of some Binary Palladium Alloys. Proc. Phys. Soc. 1962, 80, 1143. [CrossRef]

40. Das, S.S.; Kopnov, G.; Gerber, A. Kinetics of the lattice response to hydrogen absorption in thin Pd and CoPd films. Molecules 2020, 25, 3597. [CrossRef] [PubMed] 
41. Ishida, K.; Nishizawa, T. The Co-Pd (Cobalt-Palladium) system. J. Phase Equilib. 1991, 12, 83. [CrossRef]

42. Akamaru, S.; Kimura, A.; Hara, M.; Nishimura, K.; Abe, T. Hydrogenation effect on magnetic properties of Pd-Co alloys. J. Magn. Magn. Mater. 2019, 484, 8. [CrossRef]

43. Gerber, A.; Kopnov, G.; Karpovski, M. Hall effect spintronics for gas detection. Appl. Phys. Lett. 2017, 111, 143505. [CrossRef]

44. Das, S.S.; Kopnov, G.; Gerber, A. Detection of hydrogen by the extraordinary Hall effect in CoPd alloys. J. Appl. Phys. 2018, 124, 104502. [CrossRef]

45. Harumoto, T.; Nakamura, Y.; Shi, J. Correlation among hydrogenation, magnetoelastic coupling, magnetic anisotropy, and magnetoresistance in magnetostrictive, hydrogen-absorbing palladium-cobalt alloy films for hydrogen sensing. Int. J. Hydrog. Energy 2021, 46, 30204. [CrossRef]

46. Sonwane, C.G.; Wilcox, J.; Ma, Y.H. Achieving optimum hydrogen permeability in PdAg and PdAu alloys. J. Chem. Phys. 2006, 125, 184714. [CrossRef] [PubMed]

47. Flanagan, T.B.; Wang, D. Hydrogen permeation through fcc Pd-Au alloy membranes. J. Phys. Chem. C 2011, 115, 11618. [CrossRef]

48. Namba, K.; Ogura, S.; Ohno, S.; Di, W.; Kato, K.; Wilde, M.; Pletikosic, I.; Pervan, P.; Milun, M.; Fukutani, K. Acceleration of hydrogen absorption by palladium through surface alloying with gold. Proc. Natl. Acad. Sci. USA 2018, 115, 7896. [CrossRef] 